$R M x A C, \mathbf{5 3}, 59-60(2021)$

(C) 2021: Instituto de Astronomía, Universidad Nacional Autónoma de México

https://doi.org/10.22201/ia.14052059p.2021.53.15

\title{
DAG-MAM AND REMOTE CONTROL SYSTEM (UKEP)
}

\author{
R. Balbay ${ }^{1}$, O. F. Aydemir ${ }^{1}$, I. Ozturk ${ }^{1}$, and C. Yesilyaprak ${ }^{1}$
}

\section{RESUMEN}

Una de las dificultades que han surgido durante el proyecto DAG-MAM ha resultado ser el acceso a los dispositivos. Un prototipo ha sido producido (materializado en UKEP) para eliminar esta deficiencia en el sistema DAG-MAM. Se ha desempeñado adecuadamente en comparación con los dispositivos que pueden considerarse como equivalente en el mercado.

\section{ABSTRACT}

One of the problems that arise during the DAG-MAM project is the problem of access to the devices. A prototype has been produced for the idea of UKEP which designed to eliminate the deficiency in the DAGMAM system. It has performed sufficiently compared to the devices that can be considered as equivalent in the market.

Key Words: instrumentation: miscellaneous — telescopes

\section{INTRODUCTION}

Eastern Anatolia Observatory (DAG) planned to completion in 2020, Turkey's largest-diameter mirror (mirror diameter of 4 meters) is an observatory with telescope project. VIS and NIR observations will be made on the telescope with active and adaptive optical technology. The observatory is approximately 25 kilometers away from the city of Erzurum and at an altitude of 3170 meters. In order to provide meteorological and astronomical data to the observatory, MAM (Meteorological and Astronomical Monitoring System) project was implemented.

One of the problems that arise during the DAGMAM project is the problem of access to the devices. Because of this reason remote control switches which were commonly found in the market at the beginning were purchased. Since these switches are commercial products, it was understood that they were not suitable for observatory conditions and the idea that would constitute the content of this article emerged.

\section{REMOTE CONTROL SYSTEM (UKEP)}

UKEP, which means an electrical panel that can be controlled remotely, is essentially an idea rather than a device or electronic circuit. This idea is basically a system that is resistant to ambient conditions and easy to use semi-amateur, semi-professional sensors and products. This allows enthusiasts to create their own UKEP systems using sensors and electronic circuits that can be easily found. At the core

\footnotetext{
${ }^{1}$ Ataturk University Astrophysics Reseacrh and Application Center (ATASAM), 25240, Yakutiye, Erzurum, Turkey (recep.balbay@atauni.edu.tr).
}

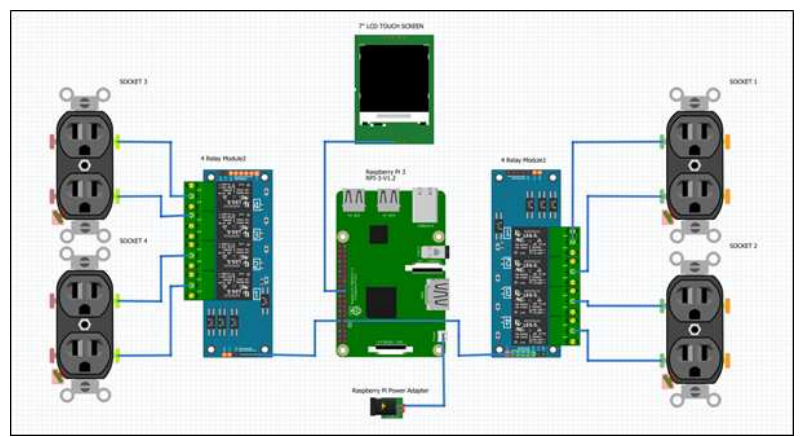

Fig. 1. Diagram of the UKEP system. The scheme is an example representation. Actual cable connections will vary according to the system to be designed.

of the UKEP idea is the remote control work using an IoT device such as Raspberry Pi. As it is known, Raspberry Pi is an easily available development platform. However, enthusiasts can develop their own UKEP systems using other popular development platforms (Arduino, Orange Pi, etc.).

Other main components of the UKEP system are relay circuit boards and IP certified panels. The number of relay cards can be scaled for the system to be designed. Two relay circuit boards are used in our own system. A total of eight electrical devices can be controlled by four relays on each board. Figure 1 shows the circuit diagram of the UKEP prototype.

Another feature that makes the UKEP idea powerful is that it is programmed in Python as the software language. Sub-libraries (PyQt 5, GPIO, etc.) used in conjunction with the Python language turn from idea to practice. 


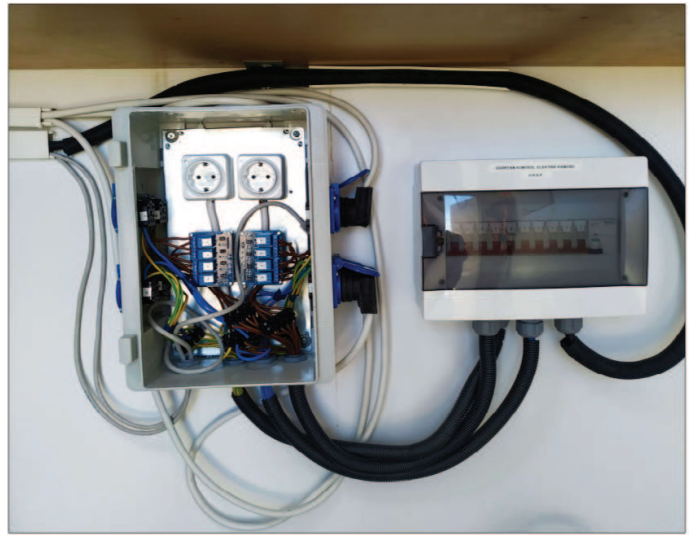

Fig. 2. An image of the DAG-MAM UKEP prototype. Fuses are used to ensure electrical safety.

\section{SCALABLE-POWERFUL PLATFORM}

The 7" touch screen is used for the prototype designed in DAG-MAM system. Using this screen, the desired sockets can be controlled from the interface (GUI). This makes it possible to control the relevant devices through the field officials when remote control is not possible.

What makes the UKEP system different from other remote control switches or relays available on the market is its customizable structure. It is a system that can switch the energies on or off according to the reactions of the devices desired to control.
For example, if a camera stops transferring after a while, the recording system or computer to which it is connected can see that the camera is active without any problems. However, the camera image is actually frozen. UKEP can recognize this situation and the power of the camera can be cut off to restart the system.

UKEP can also provide information (email, SMS, notification, etc.) to users. One of the other features of the UKEP system is that it can be connected to a remote desktop from a computer environment. Remote connection tools such as SSH, VNC, Anydesk can be connected to the UKEP system and the device can be controlled.

\section{CONCLUSION}

A prototype has been produced for the idea of UKEP which designed to eliminate the deficiency in the DAG-MAM system. The prototype device is actively used in DAG-MAM system. It has performed sufficiently compared to the devices that can be considered as equivalent in the market.

The pros of the project are mainly: fully customizable structure, remote and where necessary onsite control by various methods and finally costeffective. UKEP system is an open source project and can be developed by enthusiastics.

Acknowledgements: This work is funded under Dogu Anadolu Gozlemevi Project (2011K120230, Ministry of Development) and made use of insfracture and facilities provided by ATASAM. 